\title{
Influencia de las auxinas sobre el enraizamiento in vitro de microtallos de Nothofagus glauca (Phil.) Krasser
}

\section{Influence of auxins on in vitro rooting of microshoots of Nothofagus glauca (Phil.) Krasser}

\author{
Matilde E. Uribe ${ }^{* 1}$, José Ulloa ${ }^{1}$, Catherine Delaveau ${ }^{1}$, Katia Sáez $^{2}$, Fernando Muñoz ${ }^{3}$ \& Priscila \\ CARTES $^{1}$
}

1Universidad de Concepción, Facultad de Ciencias Forestales y Centro de Biotecnología, Casilla 160-C, Concepción, Chile. ${ }^{2}$ Universidad de Concepción, Facultad de Ciencias Físicas y Matemáticas, Avda. Esteban Iturra s/n - Barrio Universitario, Concepción, Chile.

${ }^{3}$ Universidad de Concepción, Depto. Silvicultura, Facultad de Ciencias Forestales, Casilla 160-C, Concepción, Chile.

*muribe@udec.cl

\begin{abstract}
RESUMEN
Nothofagus glauca posee una situación privilegiada en asociaciones con especies problemáticas como Nothofagus alessandrii, Beilschmiedia berteroana y Nothofagus leonii, esto multiplica su valor ecológico y paisajístico, por las relaciones en su hábitat nativo. $N$. glauca se considera clave en determinados hábitats y su pérdida o continua disminución puede afectar directamente a otras especies. La conservación ex situ es una prioridad para el rescate de la especie, por tanto el cultivo de tejidos es, entre otros, uno de los mecanismos alternativos de propagación y conservación de las especies. El objetivo de este estudio fue evaluar el efecto independiente de dos auxinas, ácido naftalenacético (ANA) y ácido 3 indolbutírico (AIB), en el enraizamiento in vitro de microtallos de $N$. glauca provenientes de subcultivos sucesivos en medio MS como sustrato. Se establecieron seis tratamientos con: $1 \mathrm{mgl}^{-1}, 3 \mathrm{mgl}^{-1}$ y $5 \mathrm{mgl}^{-1}$ de ANA y AIB, un control libre de hormonas y cuatro réplicas de cada uno. Se evaluó la supervivencia y enraizamiento de los microtallos, longitud de raíz $(\mathrm{mm})$ y número de raíces por explanto. Se obtuvo supervivencia de hasta $100 \%$ con la adición de $3 \mathrm{mgl}^{-1}$ de AIB al medio de cultivo. Se presentaron diferencias significativas entre el tratamiento control y microtallos sometidos a inmersión en hormonas. Se obtuvo 87,5\% de enraizamiento adventicio con $1 \mathrm{mgl}^{-1}$ de AIB y un 75,0\% con $3 \mathrm{mgl}^{-1}$ de ANA. Se concluye que la presencia de auxinas en el medio de cultivo es indispensable para la formación de raíces in vitro y establece la posibilidad de mantener el potencial rizogénico de la especie en condiciones ex vitro.
\end{abstract}

Palabras clave: Ácido 3-indolbutírico, ácido 1-naftalenacético, raíces adventicias, Nothofagus glauca.

\begin{abstract}
Nothofagus glauca forms essential associations with problematic species such as Nothofagus alessandrii, Beilschmiedia berteroana and Nothofagus leonii. By enhancing its native environment, $N$. glauca increases its ecological and scenic value. It is considered a keystone species in certain habitats, and its continued decline or loss may directly affect other species. Ex situ conservation is a priority for the recovery of the species; therefore, tissue culture is, among others, one of the alternative mechanisms for effective propagation and conservation of $N$. glauca. The aim of this study was to evaluate the independent effect of two auxins, 1-naphthalene acetic acid (NAA) and indole 3-butyric acid (IBA) in vitro rooting of microshoots of N. glauca from successive subcultures on MS medium. Six treatments were established containing $1 \mathrm{mgl}^{-1}, 3 \mathrm{mgl}^{-1}$, and $5 \mathrm{mgl}^{-1}$ of NAA and IBA. Experimental design included a hormone-free control and four replicates of each treatment. We evaluated the survival and rooting of the microshoots, the root length $(\mathrm{mm})$, and the number of roots formed per explant. Survival of microshoots was recorded at $100 \%$ when $3 \mathrm{mgl}^{-1}$ IBA was added to the culture medium. Furthermore, significant differences existed between the control treatment and the microshoots subjected to hormone immersion. $87.5 \%$ adventitious root formation was observed with $1 \mathrm{mgl}^{-1} \mathrm{IBA}$, and $75.0 \%$ was observed with $3 \mathrm{mgl}^{-1}$ of NAA. The results indicate that the presence of auxin in the culture medium is essential for in vitro root formation and provides the ability to maintain the rhizogenic potential of the species in ex vitro conditions.
\end{abstract}

KeYwords: Indole 3-butyric acid, 1-naphthaleneacetic acid, adventitious rooting, Nothofagus glauca. 


\section{INTRODUCCIÓN}

Nothofagus glauca (Phil.) Krasser es endémica de la zona Central de Chile, y muestra una distribución fragmentada en la Cordillera de la Costa y de los Andes. Su área de distribución se encuentra limitada entre la VI Región de O'Higgins, en la provincia del Cachapoal (3352'S), hasta la VIII Región del Bío-Bío, en la provincia del BíoBío (37²7' S; 7158' W) (Le Quesne \& Sandoval 2001, Hechenleitner et al. 2005), en asociación estrecha con otras especies del bosque nativo.

El nombre común es hualo o roble maulino y es la especie más representativa de los bosques mediterráneos del género. El hualo es un árbol de gran importancia forestal, que puede superar los $30 \mathrm{~m}$ de altura y su tronco puede alcanzar 1 ó $2 \mathrm{~m}$ de diámetro (Fajardo \& Alaback 2005). Su madera resistente y de buena calidad se usó frecuentemente para vigas, estacas y construcción, pero actualmente su uso se limita a leña y carbón. El incremento periódico anual en diámetro puede alcanzar hasta los 1,74 cm (Drake et al. 2003); sin embargo, por su escasez en los medios naturales, es importante promover una política de gestión sustentable, que incluya medidas silvícolas, de forestación y de conservación de la diversidad genética.

El manejo forestal inadecuado o sobreexplotación de la especie ha provocado que en la actualidad sea considerada especie "vulnerable" por la Unión Internacional para la Conservación de la Naturaleza (UICN 2001). En tal sentido, esta especie se encuentra protegida en la zona de los Andes, específicamente en la Región del Maule en la Reserva

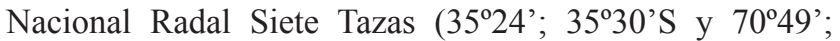
$\left.71^{\circ} 03^{\prime} \mathrm{O}\right)$ y Altos de Lircay $\left(35^{\circ} 32^{\prime} ; 35^{\circ} 40^{\prime}\right.$ 'S y $70^{\circ} 50^{\prime}$; $71^{\circ} 03^{\prime}$ O). En la Cordillera de la Costa, donde ha sufrido deforestación y sustitución por plantaciones forestales, está protegida dentro de la Reserva Nacional Los Ruiles

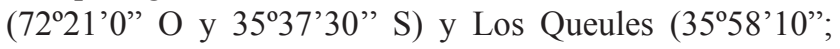
$35^{\circ} 59^{\prime} 10^{\prime \prime} \mathrm{S}$ y $72^{\circ} 42^{\prime} 30^{\prime \prime} \mathrm{O}$ (Hechenleitner et al. 2005).

De acuerdo a lo señalado por Acevedo \& Urra (2002), la capacidad germinativa de las semillas de $N$. glauca es en promedio para todas las procedencias cerca de un $40 \%$. Sin embargo, existe una alta variabilidad y hay algunas procedencias de la distribución andina que no superan el $5 \%$, lo que concuerda con lo indicado por Burgos et al. (2007) respecto a que la reproducción sexual de la especie se ve seriamente afectada debido a la predación de su semilla por insectos del género Perzelia que causa la pérdida de $57 \%$ de las unidades reproductivas antes de su dispersión, provocando bajas tasas de germinación (inferiores a 3\%), afectando la variabilidad de la especie. Otros autores señalan valores promedios superiores al $84 \%$ de germinación para semillas con 47 a $56 \%$ de viabilidad (Santelices et al. 1996, 2006). Estos antecedentes muestran la urgencia de establecer estrategias de propagación para realizar futuros programas de conservación ex situ, dentro de los cuales el cultivo in vitro es una excelente herramienta. Puede constituir una etapa clave para el establecimiento de un banco de germoplasma de esta especie, especialmente en la Cordillera de la Costa, cuyas poblaciones son reducidas y fragmentadas, siendo difíciles de propagar en su ambiente natural (Martínez-Pastur et al. 1997, Donoso 2006, INFOR 2010), lo cual indudablemente tiene un valor no sólo para la investigación, sino también para preservar especies amenazadas (Martin et al. 2006, Raju \& Prasad 2007).

Durante la propagación in vitro, la etapa de enraizamiento se presenta a menudo como una fase crítica y difícil en la mayoría de las especies leñosas (Hartmann et al. 2002). La utilización exógena de auxinas naturales como ácido indol3-acético (AIA) o sintéticas como ácido naftalenacético (ANA) y ácido 3-indolbutírico (AIB), permite manejar esta fase problemática estimulando células indiferenciadas que promueven la iniciación del enraizamiento o emergencia de raíces adventicias (Woodward \& Bartel 2005, Flores et al. 2009).

Diferentes protocolos de micropropagación se han desarrollado para el género Nothofagus (Martínez-Pastur \& Arena 1996, Martínez-Pastur et al. 1997) y el enraizamiento in vitro ha entregado resultados cuando se aplican condiciones de oscuridad, distintos tipos y concentraciones de auxinas, y aclimatación gradual en invernadero (Martínez-Pastur et al. 1997, 2003, 2007). Sin embargo, se encontró sólo un antecedente para la especie en estudio, con 93,3\% de microplantas enraizadas con $1,0 \mathrm{mgl}^{-1}$ de AIB y un porcentaje de supervivencia de 40\% (Cardemil 2000).

Santelices \& Cabello (2006) muestran que es posible lograr porcentajes de arraigamiento de un $88 \%$ con estacas provenientes de material adulto mediante el uso de AIB en camas de arraigamiento y con diferentes sustratos. Sin embargo, esto depende de factores como año de cosecha, genotipo del árbol madre, sustrato y de altas concentraciones de auxinas, las que son utilizadas en condiciones ex vitro.

Debido a la escasa información en el área y a la importancia de la especie en estudio, el objetivo de este trabajo fue evaluar el efecto independiente de dos auxinas, AIB y ANA, en el enraizamiento in vitro de microtallos de $N$. glauca obtenidos a partir de subcultivos sucesivos.

\section{MATERIALES Y MÉTODOS}

\section{Material Vegetal}

El material vegetal se obtuvo de semillas de la Reserva Nacional "Los Queules", las cuales se sumergieron en agua corriente durante $48 \mathrm{~h}$. Luego se realizó una asepsia superficial en una solución de etanol al 70\% (v/v) durante 3 min y un enjuague en agua destilada estéril, seguido de un lavado en una solución de hipoclorito de sodio comercial al $50 \%\left(\mathrm{v} / \mathrm{v}\right.$; Clorinda ${ }^{\circledR}, 5 \%$ cloro activo) por 20 min más 2 gotas de surfactante. Finalmente se realizaron tres enjuagues 
sucesivos en agua destilada estéril de 3, 4 y 5 min. Después los embriones fueron establecidos en medio MS (Murashige $\&$ Skoog 1962) subcultivados cada 30 días hasta obtener un tercer subcultivo.

\section{Condiciones de Cultivo}

Tras el establecimiento de cadenas proliferativas vía organogénesis directa, se seleccionaron microtallos que poseían un diámetro de tallo de aproximadamente $2 \mathrm{~mm}$ y $3 \mathrm{~cm}$ de longitud, provenientes del tercer subcultivo. Se dispusieron en medio base MS con $\mathrm{pH}$ ajustado a 5,8, suplementado con $30 \mathrm{gl}^{-1}$ de sacarosa y $7 \mathrm{gl}^{-1}$ de agar-agar ${ }^{\circledR}$ Merck durante 30 días. Después los microtallos fueron dispuestos en medio MS con los macronutrientes diluidos a un $25 \%$, en presencia de auxinas y en ausencia de reguladores de crecimiento (Tabla I), mantenidos durante 30 días.

Finalmente los microtallos fueron dispuestos en medio MS base sin reguladores del crecimiento por 30 días para su evaluación y previa aclimatación. Todo el proceso de proliferación e inducción rizogénica se realizó en una cámara de crecimiento controlado (Famure Ltda.) a una temperatura de $25 \pm 2{ }^{\circ} \mathrm{C}$, con una humedad relativa del $60 \%$, fotoperiodo de $16 \mathrm{~h}$ luz y densidad de flujo fotónico de $30 \mu \mathrm{mol} \mathrm{m}^{-2} \mathrm{~s}^{-1}$.

\section{VARIABLES EVALUADAS}

Durante los 30 días de inducción rizogénica se realizaron mediciones de número de raíces a la segunda, tercera y cuarta semana, en esta última se midió también la longitud de la raíz $(\mathrm{mm})$, el enraizamiento (\%) y la supervivencia (\%).

\section{AnÁLISIS ESTADÍSTICO}

La unidad experimental correspondió a cuatro microtallos dispuestos individualmente en recipientes de vidrio con $25 \mathrm{~mL}$ de medio de cultivo y se realizaron cuatro repeticiones para cada unidad. El análisis de varianza fue de entrada simple de Kruskal-Wallis, con rangos para su aplicación y se usa en más de dos muestras pequeñas e independientes, como en este estudio. Además, se utilizó la prueba de Tukey $(\mathrm{p} \leq 0,05)$ para comparar medias de los tratamientos.

\section{RESULTADOS}

La supervivencia de los explantes osciló entre 87 y $100 \%$ en todos los tratamientos incluyendo el control (Tabla II), no existiendo diferencias significativas entre los tratamientos.

El porcentaje de enraizamiento obtenido tanto para los tratamientos con AIB como con ANA no presentó diferencias significativas entre ellos, pero sí con el tratamiento control. Mientras que el análisis estadístico reveló que hubo diferencias significativas en las variables evaluadas longitud de raíz y porcentaje de enraizamiento con respecto al tratamiento testigo. La aplicación de AIB influyó significativamente $(p<0,05)$ en el porcentaje de microtallos con mayor número promedio de raíces $(5,1)$ y longitud de éstas (12,7 mm) (Tabla II). En cambio, la concentración de ANA no incidió significativamente en estas variables evaluadas.

TABla I. Concentraciones de auxinas aplicadas en los tratamientos de enraizamiento de Nothofagus glauca, durante 30 días.

TABLE I. Auxin concentrations applied in the rooting treatments of Nothofagus glauca, during 30 days.

\begin{tabular}{ccc}
\hline & \multicolumn{2}{c}{ Auxinas $\left(\mathrm{mg} \mathrm{L}^{-1}\right)$} \\
\cline { 2 - 3 } Tratamiento & AIB & ANA \\
\hline T0 & 0.0 & 0.0 \\
T1 & 1.0 & 0.0 \\
T2 & 3.0 & 0.0 \\
T3 & 5.0 & 0.0 \\
T4 & 0.0 & 1.0 \\
T5 & 0.0 & 3.0 \\
T6 & 0.0 & 5.0 \\
\hline
\end{tabular}

$\mathrm{AIB}=$ ácido 3-indolbutírico; ANA = ácido naftalenacético. T0 = testigo.

IBA $=$ indole 3-butyric acid; NAA = 1-naphthalene acetic acid. T0 = control 
TABLA II. Efecto de la concentración de auxinas en la rizogénesis de microtallos de Nothofagus glauca, en condiciones in vitro.

TABLE II. Effect of auxin concentration in the rhizogenesis of microshoots of Nothofagus glauca, subjected to in vitro conditions.

\begin{tabular}{ccccc}
\hline Tratamiento & Número de Raíces & Longitud de Raíces $(\mathrm{mm})$ & $\begin{array}{c}\text { Supervivencia } \\
(\%)\end{array}$ & $\begin{array}{c}\text { EnRaizamiento } \\
(\%)\end{array}$ \\
\hline T0 & $0 \mathbf{a}$ & $0.0 \mathbf{a}$ & $87.5 \mathbf{a}$ & $0.0 \mathbf{a}$ \\
$\mathrm{T} 1$ & $3.1 \mathbf{c d}$ & $12.7 \mathbf{c}$ & $87.5 \mathbf{a}$ & $87.5 \mathbf{b}$ \\
$\mathrm{T} 2$ & $5.1 \mathbf{d}$ & $4.0 \mathbf{b}$ & $100.0 \mathbf{a}$ & $87.5 \mathbf{b}$ \\
$\mathrm{T} 3$ & $2.0 \mathbf{b c}$ & $3.3 \mathbf{b}$ & $93.8 \mathbf{a}$ & $68.8 \mathbf{b}$ \\
$\mathrm{T} 4$ & $0.9 \mathbf{a b}$ & $5.3 \mathbf{b}$ & $87.5 \mathbf{a}$ & $43.8 \mathbf{a b}$ \\
$\mathrm{T} 5$ & $2.8 \mathbf{b c}$ & $4.9 \mathbf{b}$ & $87.5 \mathbf{a}$ & $75.0 \mathbf{b}$ \\
$\mathrm{T} 6$ & $2.0 \mathbf{b c}$ & $5.7 \mathbf{b}$ & $93.8 \mathbf{a}$ & $56.3 \mathbf{a b}$ \\
\hline
\end{tabular}

$\mathrm{T} 0=$ testigo; $\mathrm{T} 1=1,0 \mathrm{mg} \mathrm{l}^{-1} \mathrm{AIB} ; \mathrm{T} 2=3,0 \mathrm{mg} \mathrm{l}^{-1} \mathrm{AIB} ; \mathrm{T} 3=5,0 \mathrm{mg} \mathrm{l}^{-1} \mathrm{AIB} ; \mathrm{T} 4=1,0 \mathrm{mg} \mathrm{l}^{-1} \mathrm{ANA}$; $5=3,0 \mathrm{mg} \mathrm{l^{-1 }}$ ANA; T6 = 5,0 mg $1^{-1}$ ANA. Letras distintas indican diferencias significativas $(\mathrm{p} \leq 0,05)$.

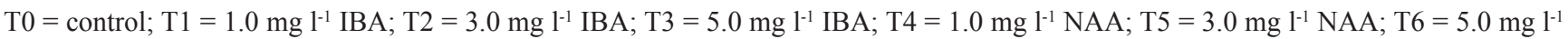
NAA. Different letters indicate significant differences $(\mathrm{p} \leq 0.05)$.

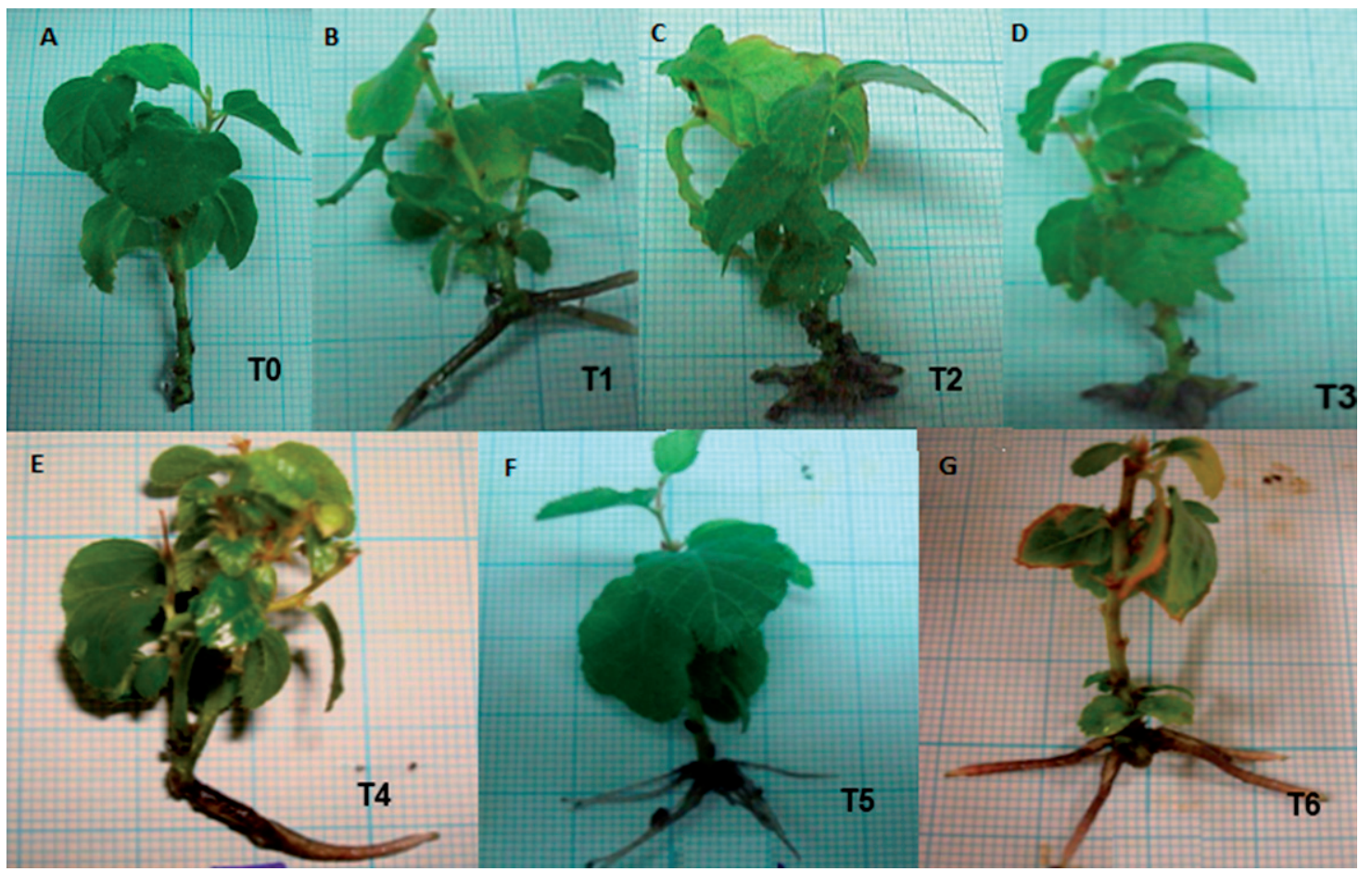

Figura 1. Formación de raíces adventicias en microtallos de Nothofagus glauca. A. T0= testigo; B. T1 = 1,0 mg ${ }^{-1} \mathrm{AIB} ; \mathrm{C}$ T2 $=3,0 \mathrm{mgl}^{-1}$ AIB; D. T3 = 5,0 $\mathrm{mgl}^{-1}$ AIB; E. T4 $=1,0 \mathrm{mgl}^{-1}$ ANA; F. T5 $=3,0 \mathrm{mgl}^{-1}$ ANA; G. T6 $=5,0 \mathrm{mgl}^{-1}$ ANA.

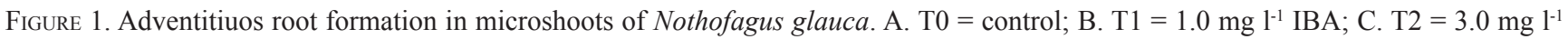
IBA; D. T3 = $5.0 \mathrm{mg} \mathrm{l}^{-1} \mathrm{IBA}$; E. T4 = 1,0 $\mathrm{mg} \mathrm{l}^{-1} \mathrm{NAA}$; F. T5 = $3.0 \mathrm{mg} \mathrm{l}^{-1} \mathrm{NAA}$; G. T6 = $5.0 \mathrm{mg} \mathrm{l}^{-1} \mathrm{NAA}$.

En el tratamiento control, sin reguladores del crecimiento en el medio de cultivo, no se evidenciaron raíces adventicias en los microtallos (Fig. 1A). Es importante señalar que los mayores porcentajes de microtallos enraizados se obtuvieron en presencia de bajas concentraciones de AIB
(Figs. 1B, 1C) con 87,5\% de enraizamiento en ambos casos (T1 y T2).

La morfología externa de las raíces obtenidas en cada tratamiento indica que el aumento de la concentración de AIB al medio de cultivo disminuyó significativamente 
la longitud promedio de las raíces (Fig. 1, Tabla II). El aumento de la concentración de AIB provocó un incremento en la formación de tejido callogénico y un mayor número de raíces (Figs. 1C, 1D). Los microtallos enraizados con la aplicación de ANA no mostraron diferencias significativas entre la longitud promedio de sus raíces y número de raíces (Figs. 1E, 1F, 1G). No obstante, la transferencia de los microtallos a medio libre de reguladores del crecimiento, posterior al ensayo de inducción, permitió apreciar diferencias visuales entre raíces expuestas a ANA y AIB. Las primeras presentaban raíces vitrificadas, muy frágiles que se desprendían con facilidad del resto del tejido, mientras que aquéllas provenientes del tratamiento con AIB presentaban raíces firmes y aparentemente funcionales para la fase de aclimatación.

En general, el comportamiento de los microtallos sometidos a los ensayos de inducción con AIB y ANA, durante las 2, 3 y 4 semanas (Fig. 2), arroja una disminución de la producción de raíces adventicias con el aumento de la concentración hormonal y con el tiempo de permanencia de los microtallos en el medio de inducción. Por lo tanto, la producción de raíces adventicias se incrementa, especialmente a bajas concentraciones de ácido indolbutírico.

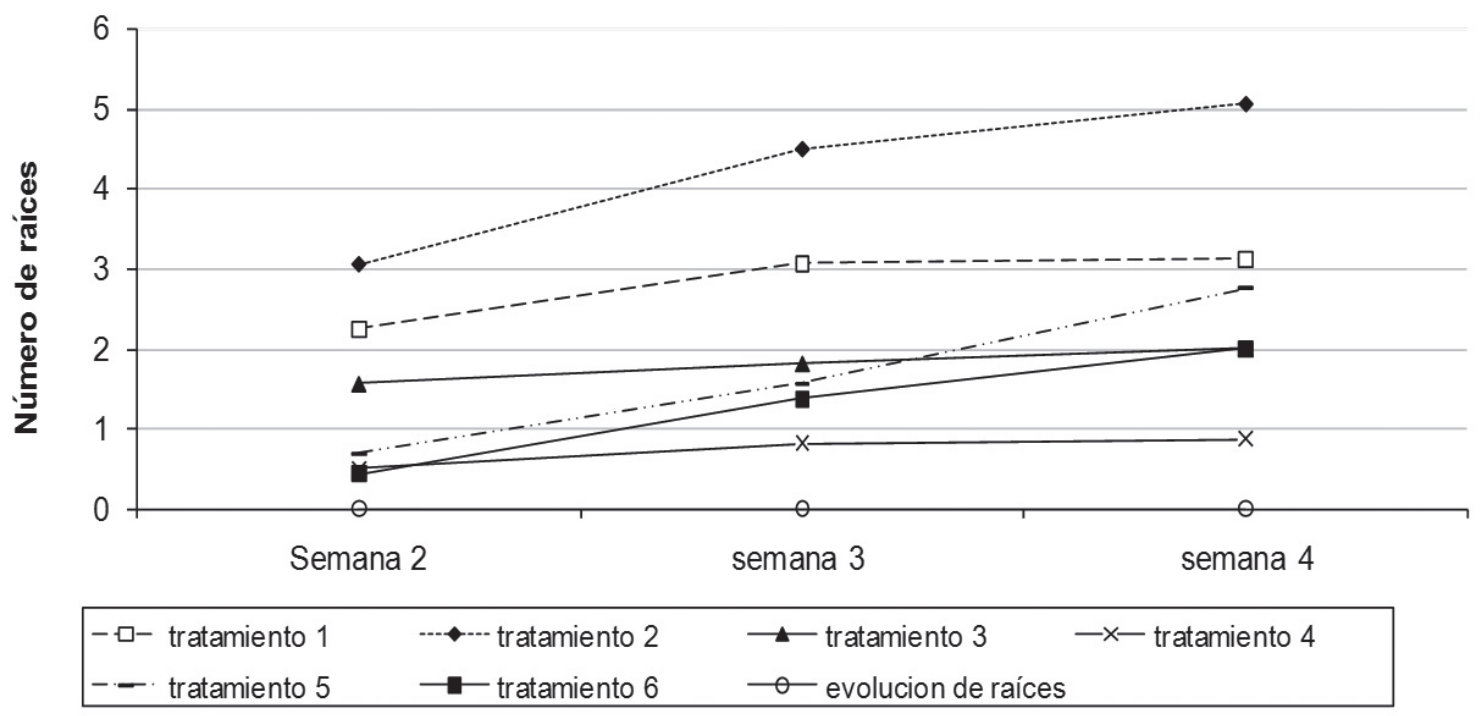

Figura 2. Incremento del número de raíces en microtallos de Nothofagus glauca durante las cuatro semanas que duró el ensayo. T1 $=1,0$ $\mathrm{mg} \mathrm{l}^{-1} \mathrm{AIB} ; \mathrm{T} 2=3,0 \mathrm{mg} \mathrm{l}^{-1} \mathrm{AIB}$; T3 = 5,0 $\mathrm{mg} \mathrm{l}^{-1} \mathrm{AIB}$; T4 = 1,0 $\mathrm{mg} \mathrm{l}^{-1}$ ANA; T5 = 3,0 $\mathrm{mg} \mathrm{l}^{-1}$ ANA; T6 = 5,0 mg ${ }^{-1}$ ANA.

FIGURE 2. Increase in the number of roots in microshoots Nothofagus glauca during four weeks of study. T1 = $1.0 \mathrm{mg}{ }^{-1} \mathrm{IBA}$; $\mathrm{T} 2=3.0 \mathrm{mg}$ $\mathrm{l}^{-1} \mathrm{IBA} ; \mathrm{T} 3=5.0 \mathrm{mg} \mathrm{l}^{-1} \mathrm{IBA} ; \mathrm{T} 4=1,0 \mathrm{mg} \mathrm{l}^{-1} \mathrm{NAA}$; $5=3.0 \mathrm{mg} \mathrm{l}^{-1} \mathrm{NAA} ; \mathrm{T} 6=5.0 \mathrm{mg} \mathrm{l}^{-1} \mathrm{NAA}$.

\section{DISCUSIÓN}

Los resultados indican que el material vegetal tuvo una buena adaptación y respuesta a las condiciones de enraizamiento, lo cual se manifiesta en el alto porcentaje de supervivencia de los microtallos, situación que se ve reflejada en la falta de diferencias significativas entre los distintos tratamientos. Esto coincide con los resultados de otros estudios in vitro en especies como Juglans regia L., Eucryphia glutinosa (Poepp. et Endl.) Baillon y Castanea sativa Mill. (Ríos et al. 2005, Avilés et al. 2009, Latsague et al. 2009). No obstante, cabe destacar que los altos niveles de supervivencia obtenidos pueden ser un indicador de la calidad inicial de los microtallos utilizados en este ensayo, ya que es importante considerar que, además de los contenidos hormonales, las características anatómicas y fisiológicas de las plantas micropropagadas se hacen necesarias para su supervivencia tanto en condiciones in vitro como ex vitro (Hartmann et al. 2002, Ríos et al. 2005).

A pesar de que no existen diferencias significativas entre las hormonas utilizadas, se obtiene un mayor porcentaje de enraizamiento en presencia de AIB. Algunos autores indican que esto se debe a que ANA, a concentraciones mayores o iguales a AIB, puede ocasionar inhibición de la producción de raíces por su mayor estabilidad en el medio de cultivo frente a la degradación no biológica y foto-oxidación, siendo necesaria una menor concentración en su aplicación al medio de cultivo (De Klerk et al. 1997, Latsague et al. 2009).

Por otro lado, los mayores porcentajes de enraizamiento fueron obtenidos a bajas concentraciones de AIB. El efecto positivo de concentraciones bajas de AIB fue reportado 
también en Quercus robur L., especie muy relacionada filogenéticamente con las del género Nothofagus (Hill \& Jordan 1993), donde similares resultados fueron obtenidos por Puddephat et al. (1999), con porcentajes de enraizamiento de un $87,5 \%$ en presencia de AIB y un $75 \%$ en presencia de ANA. El efecto positivo de concentraciones bajas de AIB ya ha sido reportado en la literatura por Santelices \& Cabello (2006) y Latsague et al. (2009), quienes al trabajar con estacas semileñosas de Nothofagus glauca y Eucryphia glutinosa, respectivamente, obtuvieron mejores resultados con menores concentraciones de AIB.

Caro et al. (2003) informan un 33\% de enraizamiento con una concentración de $5 \mathrm{mgl}^{-1}$ en microtallos de Nothofagus alpina (Poepp. et Endl.) Oerst., estos resultados pueden indicar que al aumentar la concentración de auxina en el medio de cultivo, ésta no ejerce una relación positiva en el porcentaje de enraizamiento. A pesar de que la concentración hormonal no influye significativamente en el porcentaje de enraizamiento en este estudio, tanto para la auxina AIB como ANA, se reporta que altas concentraciones de éstas, sumado a periodos prolongados de inducción, pueden inhibir el crecimiento y desarrollo del primordio radicular (Hartmann et al. 2002, Ríos et al. 2005, Taiz \& Zeiger 2006).

Para el crecimiento de raíces, en general se requieren bajas concentraciones de auxinas (dependiendo de la especie y la edad de la planta), debido a que las células de los meristemos radicales contienen un nivel de auxinas, provenientes de la parte aérea, suficientes para una elongación normal; no así para la formación de raíces adventicias, en donde se requieren mayores concentraciones (Taiz \& Zeiger 2006). En este sentido, con respecto a las variables número y longitud de raíces formadas, se observó variabilidad con el aumento de la concentración de auxinas. El efecto de las auxinas sobre el enraizamiento es promover a bajas concentraciones e inhibir a altas concentraciones (supraóptimo). El bajo número y longitud de raíces obtenido con ANA indica que se tienen efectos inhibitorios (formación de callo, estimulación de compuestos fenólicos, entre otros) a concentraciones relativamente bajas de esta auxina. Generalmente, el AIB se utiliza más que ANA o cualquier otra auxina en la estimulación del enraizamiento, ya que el AIB es activo a pesar de que se metaboliza con rapidez a AIB-aspartato o conjugado con un péptido (Taiz \& Zeiger 2006). Al respecto, Gaspar et al. (1994) señalan que la utilización de dosis óptimas de reguladores del crecimiento es muy importante, puesto que las concentraciones adecuadas varían para cada especie y es necesario realizar los estudios pertinentes.

La falta de raíces en el medio libre de hormonas se podría explicar debido a la ausencia de estructuras preformadas para la emergencia de primordios radiculares en la especie, lo que sí es posible encontrar en otras especies como Salix sp., Populus sp., Ribes nigrum L. o Fagus sylvatica L. (Hassing 1972, Fink 1982). De manera similar a lo que se observa en estudios realizados por Martínez-Pastur et al. (2005) y Uribe et al. (2011) donde se evidencia la carencia de estructuras pre-radiculares en Nothofagus nitida (Phil.) Krasser y Beilschmiedia berteroana (Gay) Kosterm. De ahí la importancia de la aplicación de agentes inductores como las auxinas, así como también la utilización de otros reguladores del crecimiento vegetal, que se conoce juegan un rol importante en este tipo de respuesta (Martínez-Pastur et al. 2007).

En este contexto, un sistema radical de calidad, según Vengadesan \& Pijut (2009), considera el número de raíces por microtallo o brote, longitud de las raíces y ausencia de formación de callo, características que determinan el rendimiento durante la fase de aclimatación. Por tanto, en este estudio se obtuvo un sistema radical de calidad utilizando bajas concentraciones de AIB, contrario a lo que ocurre, por ejemplo, en Nothofagus leoni Espinosa, donde concentraciones más elevadas de AIB inducen un mejor sistema radical (Martínez-Pastur \& Arena 1999).

El número de raíces adventicias producidas durante el periodo que duró el ensayo fue aumentado paulatinamente en los microtallos, especialmente en aquéllos sometidos a bajas concentraciones de AIB. Similares respuestas se han obtenido en diferentes especies, tales como Celastrus paniculatus Willd. (Raju \& Prasad 2010), en cultivares de arándanos half-highbush blueberry 'Northland' (Zhaoa et al. 2011).

Los resultados obtenidos en este trabajo son un valioso aporte para estudios de inducción rizogénica en presencia de auxinas como AIB y ANA. Sin embargo, surge el desafío de implementar nuevos ensayos que incorporen, por ejemplo, el número de subcultivos de los microtallos, ya que la capacidad morfogénica de los tejidos se ve afectada en la mayoría de las especies leñosas de manera negativa al incrementar en número de subcultivos (Ríos et al. 2005).

Estos resultados nos permiten inferir en forma práctica las concentraciones a utilizar en forma experimental en esta especie, pero cabe señalar que es necesario, en investigaciones futuras, realizar estudios del papel decisivo que tienen las auxinas en una serie de procesos del desarrollo y crecimiento vegetal. Teniendo en cuenta la localización de la biosíntesis de las auxinas, se debe considerar que el transporte de la hormona desde los lugares de biosíntesis hasta los tejidos y órganos implicados en la respuestas, puede resultar clave en estos procesos (Acosta 2004).

\section{CONCLUSIONES}

Es necesaria la presencia de auxina exógena en el medio de cultivo para el desarrollo de raíces adventicias en microtallos de Nothofagus glauca. Además, se considera que las concentraciones de $1 \mathrm{mgl}^{-1}$ y $3 \mathrm{mgl}^{-1}$ de ácido 3-indolbutírico son adecuadas para obtener un número y longitud de raíces 
aceptable. Es importante señalar que la supervivencia alta obtenida en todos los tratamientos evaluados permite continuar con las etapas de enraizamiento y aclimatación de microtallos de esta especie.

\section{AGRADECIMIENTOS}

Trabajo financiado por la Universidad de Concepción (Chile) a través del proyecto DIUC No 207.142.029-1.0 de la Dirección de Investigación.

\section{BIBLIOGRAFÍA}

Acosta, M. 2004. Función del transporte polar y lateral en la formación de gradientes longitudinal y radial de auxina. Relación con el crecimiento, el enraizamiento y los valores de ploidía celular. Universidad de Murcia. En: Metabolismo y modo de acción de fitohormonas. Ed. Universidad de Salamanca, España. 41 pp.

Acevedo, S. \& C. UrRa. 2002. Caracterización de procedencias en la etapa de viverización de Nothofagus alessandri Espinosa (Ruil) y Nothofagus glauca (Phil.) Krasser (Hualo). En: Donoso C. Las especies arbóreas de los bosques templados de Chile y Argentina. Autoecología. 433-442.

Avilés, F., D. Ríos, R. González \& M. Sánchez-Olate. 2009. Effect of culture medium in callogenesis from adult walnut leaves (Juglans regia L.). Chilean Journal of Agricultural Research 69(3): 460-467.

Burgos, A., A. Grez \& R. Bustamante. 2007. Seed production, predispersal seed predation and germination of Nothofagus glauca (Nothofagaceae) in a temperate fragmented forest in Chile. Forest Ecology and Management 255(3-4): 12261233.

CArdemil, C.A. 2000. Enraizamiento in vitro de tres especies de Nothofagus endémicas de la zona mesomórfica de Chile. Tesis de Grado para optar al título de licenciado en Agronomía. Facultad de Ciencias Agrarias. Universidad Austral de Chile. 114 pp.

Caro, L., N. Santecchia, P. Marinangeli, N. Curvetto \& L. Hernández. 2003. Agrobacterium rhizogenes vs. auxinic induction for in vitro rhizogenesis Prosopis chilensis and Nothofagus alpina. Biocell 27(3): 311-318.

De Klerk, G., J. Ter Brugge \& S. Marinova. 1997. Effectiveness of IAA, IBA and NAA during adventitious root formation in vitro in Malus "Jork 9". Plant Cell Tissue Organ Culture 49: 39-44.

Donoso, C. 2006. Las especies arbóreas de los bosques templados de Chile y Argentina. Autoecología. Ediciones Marisa Cuneo, Chile. 678 pp.

Drake, F., A. Emanuelli \& E. Acuña. 2003. Compendio de Funciones Dendrométricas del Bosque Nativo. Universidad de Concepción y Proyecto conservación y manejo sustentable del bosque nativo. Santiago, Chile. 197 pp.

Fajardo, A. \& P. Alaback. 2005. Effects of natural and human disturbances on the dynamics and spatial structure of Nothofagus glauca in south-central Chile. Journal
Biogeography 32: 1811-1825.

FINK, S. 1982. Adventitious root primordia-the cause of abnormally broad xylem rays in hard and softwoods. International Association of Wood Anatomists 3: 31-38.

Flores, C.M., A. Cabañas, I. Peñalosa, R. Quintanar, J. Vázquez \& M. UrzúA. 2009. Auxinas endógenas, AIA-Oxidasa y enraizamiento en Vigna radiata L. Wilczek inducido por auxina exógena libre y conjugada. Revista Fitotecnia México 32(1): 61-66.

Gaspar, T., C. Kevers, J.F. Hausman \& V. Ripetti. 1994. Peroxidase activity and endogenous free auxin during adventitious root formation. In: P.J. Lumdsen, J.R. Nicholas \& W.J. Davies (eds.), Physiology, Growth and Development of Plants in Culture. Kluwer Acad. Pub., Dordrecht, pp. 289-298.

Hartmann, H.T., D.E. Kester, F.T. Davies \& R.L. Gèneve. 2002. Plant Propagation: Principles and Practices. Prentice Hall. $7^{\text {th }}$ Ed. 880 pp.

Hassing, B. 1972. Meristematic activity during adventitious root primordium development. Plant Physiology 4: 886-892.

Hechenleitner, P., M. Gardner, P. Thomas, C. Echeverría, B. Escobar, P. Brownless \& C. Martínez. 2005. Plantas Amenazadas del Centro-Sur de Chile. Distribución, Conservación y Propagación. Primera Edición. Universidad Austral de Chile y Real Jardín Botánico de Edimburgo, Valdivia. $188 \mathrm{pp}$.

HILL, R.S. \& G.J. JORDAN. 1993. The evolutionary history of Nothofagus (Nothofagaceae). Australian Systematic Botany 6: 111-126.

INFOR. 2010. Anuario Forestal 2010. Boletín estadístico 128. Instituto Forestal. Santiago, Chile. 134 pp.

Latsague, M., P. SÁez \& J. YÁÑez. 2009. Efecto del ácido indolbutírico en la capacidad rizogénica de estacas de Eucryphia glutinosa. Bosque 30(2): 102-105.

Le Quesne, C. \& L. Sandoval. 2001. Extensión del límite sur para Nothofagus glauca (Phil.) Krasser. Gayana Botánica 58(2): 139-142.

Martin, G., S.P. Geetha, S.S. Raja, A.V. Raghu, I. Balachandran \& P.N. RAVINDRAN. 2006. An efficient micropropagation system for Celastrus paniculatus Willd. A vulnerable medicinal plant. Journal Forest Research 11: 461-465.

Martínez-Pastur, G. \& M. Arena. 1996. In vitro propagation of Nothofagus nervosa (Phil.) Dim. et Mil. Phyton 58: 1-7.

Martínez-Pastur, G. \& M. Arena. 1999. In vitro propagation of juvenile Nothofagus leoni Espinosa (Fagaceae). Journal Forest Research 4: 295-298.

Martínez-Pastur, G., M.Arena\& O.CAso. 1997.Micropropagación de Nothofagus pumilio (Poepp. et Endl.) Krasser. Bosque 18(2): 43-50.

Martínez-Pastur, G., M. Arena, N. Curvetto, D. Zappacosta \& E. Eliasco. 2003. Successive media to improve the in vitro rhizogenesis of Nothofagus nervosa (Phil.) Dim. et Mil. New Forests 26: 201-215.

Martínez-Pastur, G., M. Arena, L. Hernández, N. Curvetto \& E. EliAsCO. 2005. Histological event during in vitro rooting of Nothofagus nervosa. New Zealand Journal of Botany 43: 61-70.

Martínez-Pastur, G., M. Arena, M.P. Benavides, E. Eliasco \& N. Curvetto. 2007. Role of polyamines during in vitro rhizogenesis of Nothofagus nervosa using successive culture media. New Forests 34: 83-93. 
Murashige, T. \& F. Skoog. 1962. A revised medium for rapid growth and bioassays with tobacco tissue cultures. Physioly Plantarum 15: 473-497.

Puddephat, I.J., P. Galderson \& N.A. Wright. 1999. In vitro root induction in axillary microshoots of Quercus robur L. Annals Applied Biology 134(2): 233-239.

Raju, N.L. \& M.N.V. Prasad. 2007. Cytokinin-induced high frequency shoot multiplication in Celastrus paniculatus Willd., a red listed medicinal plant. Medical and Aromatic Plant Science and Biotechnology 1: 133-137.

RaJu, N.L. \& M.N.V. Prasad. 2010. Influence of growth hormones on adventitious root formation in semi-hadrwood cuttings of Celastrus paniculatus Willd.: a contribution for rapid multiplication and conservation management. Agroforestry Systems 79: 249-252.

Ríos, D., F. Avilés, M. Sánchez-Olate, R. Escobar \& G. Pereira. 2005. Variación de la tasa de enraizamiento asociada al número de subcultivo y diámetro de microtallos de castaño Castanea sativa Mill. Agricultura Técnica 65(3): 258-264.

SAntelices, R. \& A. CABello. 2006. Efecto del ácido indolbutírico, del tipo de la cama de arraigamiento, del substrato, y del árbol madre en la capacidad de arraigamiento de estacas de Nothofagus glauca (Phil.) Krasser. Revista Chilena de Historia Natural 79: 55-64.

Santelices, R., C. Donoso \& A. Cabello. 2006. Nothofagus glauca (Phil.) Krasser. Hualo, Roble maulino, Roble colorado (Maule). Familia Fagaceae. En: C. Donoso (ed.), Las especies arbóreas de los bosques templados de Chile y Argentina. Autoecología. pp. 433-442. Ediciones Marisa Cuneo, Valdivia, Chile.

Santelices, R., M. Riquelme \& F. Rojas. 1996. Aspectos sobre la semilla y germinación de Nothofagus glauca (Phil.) Krasser de dos procedencias de la VII Región. Ciencia e Investigación Forestal 10(2): 297-306.

Taiz, L. \& E. Zeiger. 2006. Plant Physiology. Sinahuer Associates, Inc. $4^{\mathrm{a}}$ ed. $764 \mathrm{pp}$.

UICN. 2001. Categorías y Criterios de la Lista Roja de la UICN: Versión 3.1. Comisión de Supervivencia de Especies de la UICN. UICN, Gland. Suiza y Cambridge, Reino Unido. $33 \mathrm{pp}$.

Uribe, M.E., M. Sandoval, A. Méndez, F. Mora \& C. Delaveau. 2011. In vitro rooting of Beilschmiedia berteroana, endemic to the South Central area of Chile. Ciencia e Investigación Agraria 38(1): 107-115.

Van Telgen, H.J., A. Van Mil \& B. Kunneman. 1992. Effect of propagation and rooting conditions on acclimatization of micropropagated plants. Acta Botanica Neerlandica. 41: 453-460.

Vengadesan, G. \& P.M. PiJut. 2009. In vitro propagation of northern red oak (Quercus rubra L.). In Vitro Cell Developmental Biology-Plantarum 45: 474-482.

Woodward, A.W. \& B. Bartel. 2005. Auxin: regulation, action, and interaction. Annals of Botany 95: 707-735.

ZhaOA, X., L. ZhaN \& X. Zou. 2011. In vitro high-frequency regeneration of half-highbush 'Northland' blueberry. New Zealand Journal of Crop and Horticultural Science 39 (1): 51-59.

Recibido: 30.07 .11

Aceptado: 16.11.11 